method of placing the loopfuls separately on the glass, as recommended by Delépine, was found very reliable.

In testing, a small platinum loop of the blood solutions is mixed with as many loops of water and bouillon culture as may be needed to give the required dilution, and make the volume of the diluted blood as nearly as possible equal to that of the culture. For convenience a table of the formulæ for dilutions was made, and is useful when one is ascertaining the extreme limit of dilution possible, as this often reaches into the hundreds.

For an ordinary test-to learn, for instance, if the blood reacts at $I$ to 10-all that is necessary is to mix a loop of the stock $I$ to 5 solution with one of the culture. By mixing it with four loops of water and five of culture, a dilution of 1 to 50 is readily obtained. The time required when this simple test only is needed does not exceed five minutes.

We have made duplicate observations to ascertain the average limit of error, and find this to be about ro per cent. after some familiarity has been obtained with the method. It is much more accurate than a plan previously suggested by one of us of taking the standard of colour as a guide.

Comparative tests, when the duplicate samples consisted either of serum or of watery solutions of fresh blood taken by a Zeiss-Thoma barometer pipette, gave us results practically identical with those by the dry blood method, the latter being slightly lower, however, as a rule. So that if the dry blood showed a given intensity, the serum would show at least that, and perhaps ro per cent. more.

Drying for a few days did not make any great difference in the intensity, though it slightly lessened the reaction. We defer the publication in detail of our results until our observations are more numerous.

The result of the quantitative dry method so far has convinced us that it is delicate and accurate enough to give results sufficiently close for practical purposes or for comparison with other methods of testing. It has not yet been found necessary to use the quantitative test for the ordinary routine diagnostic work; but where the results are to be used for recording doubtful or exceptional cases for scientific publication, we think quantitative data preferable.

It does not appear necessary, however, to use quantitative tests in ordinary routine diagnostic work. Our experience has been that in no case hitherto examined by us have we been able to obtain a decisive reaction by the use of quantitative methods of fluid blood or serum, when it could not also be obtained by the dried blood test without quantitative complications.

At the same time, we fully agree with the views expressed by Professor Welch on a recent cccasion, that for scientific observations it was very desirable that the dried blood method should be also made a quantitative one, and our work in that direction was prompted by a friendly suggestion coming from him, for which we wish here to express our thanks.

REFERENCE.

1 Soc. de Biol., Jantary, 1897.

\section{THE CONDITION OF TEST CULTURES ESPECIALLY AS REGARDS TITRATION FAVOURABLE TO CLEAR SERUM REACTIONS BY THE DRIED BLOOD METHOD.}

\author{
BY
}

WYATT JOHNSTON, M.D., an l D. D. McTAGGART, [From the Laboratory of the Board of Health of the Province of Quebec ]

THIs matter was referred to in the discussion at Philadelphia on June 3rd, 1897, before the American Medical Association, by Bates Block and one of us. We found that by varying the composition of the medium and the conditions under. which the culture is kept, it is possible to obtain a culture which will yield excellent results or the reverse. We can now at will obtain a bouillon culture which can be left in contact with solutions of non-typhoid blood for 24 to 48 hours without giving any reaction, and will react promptly with typhoid blood. On the other hand, we can by neglecting certain details, get a test culture which will give one of two pseudo-reactions with almost any blood solution or serum. Pseudo-reaction $A$ is a decided clumping of over 95 per cent. of all the bacteria, but without loss of motion. Pseudo-reaction B culture with most blood solutions will show cessation of motion, with defective clumping. The former (A) we found to occur with cultures made very active by daily transplantations, and the latter (B) to growth in rather too alkaline bouillon.

Our earliest observations happened to be made with bouillon giving satisfactory results. These became unsatisfactory for a few weeks under daily transplantations and good again on returning to monthly changes of stock cultures. After a few months a change in the laboratory personnel with different assignment of duties led to the second class of pseudo-reactions troubling us for a few weeks. Attention to the reaction of the culture medium remedied this difficulty, which seemed entirely due to a trifling increase in the alkalinity of the laboratory bouillon. At another laboratory in charge of one of us there was still a supply of bouillon remaining which gave satisfactory results. This reacted 3.5 per cent. acid to phenolpthalein and just verged on the acid point with litmus. The adoption of bouillons having a reaction requiring 3.5 per cent. of normal alkali to restore the tint of phenol-phthalein led to satisfactory results once more. The reading of the end point varies somewhat with the observer and the optimum reaction varies slightly with the particular culture and the composition of the medium, but always lies between 3 and 4 per cent.

The pseudo-reactions here described occur in bouillons giving a heavy growth and some sediment at the end of twenty-four hours at $37^{\circ} \mathrm{C}$. They show a tendency to the spontaneous clumping mentioned by Widal, but this is greatly exaggerated by adding blood solution. Serum does not have the same tendency to cause pseudo-reaction A. Dilution alone did not prove in our hands a satisfactory remedy.

We believe that these anomalies explain the statements of some writers that all serums tend to cause clumping sooner or later. The optimum reaction depends somewhat on the temperature of the thermostat and the age of the culture. Satisfactory cultures show gentle clouding only at twenty-four hours, and have no sediment or serum. If the culture medium is made too acid it becomes insensitive, loses motility, and does not react promptly, but gives no pseudo-reaction.

We note for the first time in the British Medical Journal of December 4th, 1897, that Delépine had already in the JOURNAL on April $17 \mathrm{th}, 1897$, called attention to the danger of pseudo-reactions if the bouillon is alkaline. He recommends neutral bouillon, whereas we found acid bouillon preferable. The question is one of intensity of growth rather than of pure alkalinity alone, since the pseudo-reactions can also be avoided by raising the alkalinity till the growth becomes scanty. Personally, our interest lay more in deciding the most suitable reacticn for dried blood work.

\section{ON SERUM REACTION WITH BACTERIA OTHER THAN THE USUAL PATHOGENIC FORMS.} BY

WYATT JOHNSTON, M.D., and E. W. HAMMOND. [From the Pathological Laboratory, McGill University.]

Some observations made jointly by us have shown the occurrence of a serum reaction when cultures of the specific organism of the Picton cattle disease are brought in contact with the serum of cattle attacked by this disease or with that of other animals (goat, rabbit, and guinea-pig) infected with it. The blood of healthy animals did not give the reaction. It diagnostic value has not yet been thoroughly tested clinically. The reaction was obtainable in dilutions of 1 in 25 , and was evidenced by the formation of distinct clumps, the control specimens remaining free from them after many hours.

Injection of cultures sterilised by heat produced a moderate blood reaction and some degree of immunity. The results will be more fally reported elsewhere by E. W. Hammond. The organism in this disease is a small non-motile diplobacillus, the constant occurrence and specific relation of which to this disease was established some years ago-in 1893-by Dr. Adami. 
A few preliminary observations were also made jointly by myself and Mr. Hammond with a view of determining whether bacteria considered to be in the ordinary sense of the word non-pathogenic, for example, the ordinary water bacteria, could be made to give a serum reaction sufficiently marked to be of service in the differentiation of species, groups, and races. This appeared to be a desirable subject of study owing to the marked influence shown by race peculiarities in the degree of serum reaction obtained in the case of the pathogenic spirilla.

The observations are not sufficient to warrant any general conclusions, and are only mentioned here as suggesting a possible new means of diagnosis with a class of microorganisms which form a great stumblingblock to progress in the direction of systematic baeteriological classification. We gather that the agglutinative phenomena when slightly manifested serve to indicate racial, rather than specific affinities.

[I would state that while the suggestions in connection with the Picton disease observations came from me, the technical work has, subsequent to the first successful observation, been almost entirely done by Mr. E. W. Hammond. The blood samples used were the same that had been in scale tubes for from I to 3 years, and had been left in the laboratory by Dr. Adami, who was absent in England at the time.-W. J.1

\section{ON THE RED ALLY OF UROHAMATOPORPHYRIN :} A RETROSPEC 1 OF TWELVE CASES.

Bx DAVID FRASER HARRIS, M.D., B.Sc.Lond., F.R.S.E., Muirhead Demonstrator of Physiology in the University of Glasgow.

A CASE of disease is, from one point of view, a great physiological experiment performed by Nature, which often presents us with processes arrested and functions perverted at very instructive stages. The appearance in the urine of the pigment known as hrmatoporphyrin, or one of its allies, in place of the amber-eoloured pigment normally there, is an example of an arrested process - that of katabolism of pigmentary matter derived from the blood, and taking place, on the largest scale, in the liver.

The term "urohæmatoporphyrin" dates from 1885, when MacMunn, in a paper ${ }^{1}$ on the colouring matters of bile and urine, rechristened what he had five years earlier named "urohæmatin." ${ }_{2}$ In 1880 , in a case of rheumatic fever, he found "urohæmatin," and about the same date made it artificially by reduction of the pigment hæmatin. Urohæmatin was then found in a case of pericarditis, and on several occasions in the urine of Addison's disease. Since 885 this pigment has always been known as urobæmatoporphyrin; it gives to urine an orange colour, and has been detected in a number of diseases, namely, in addition to the three given above-peritonitis, meningitis, cirrhosis of liver, peritoneal blood effusion, croupous pneumonia, typhoid fever, measles, and Hodgkin's disease. ${ }^{3}$

In all these cases the colour of the urine, if not quite orange, is of a tint of amber deeper than the normal. Examined with the spectroscope, urohæmatoporphyrin shows a four-banded spectrum, the wave-lengths of whose bands are published in many of the above-mentioned monographs, but briefly put the bands are-one in the red to the left of $D$, two between $D$ and $E$, and one near the $F$ line. This spectrum closely resembles that of a laboratory pigment alkaline hæmatoporphyrin also four-banded, whose bands differ slightly from those of the urinary pigment in situation and intensity. Hæmatoporphyrin as a laboratory pigment has been long known both in acid and alkaline solutions. Thudichum in 1872 called it " cruentine." 5 The acid solution is two-banded and very characteristic, the pigment is ironfree. MacMunn found it in several of the lower animals, in the integument of certain slugs, star-fishes, the earth-worm, and in some birds' egg-shells.

Previously to 1890 this was all that could be said about hæmatoporphyrin and its urinary ally, but early in that year MacMunn saw for the first time two specimens (sent him by Dr. S. M. Copeman) of a "Burgundy-red urine" which con- tained no proteid, blood, or bile. Towards the close of the same year Mr. Cant of Lincoln, and Dr. Noêl Paton of Edinburgh, each sent MacMunn a specimen of urine similarly pigmented.

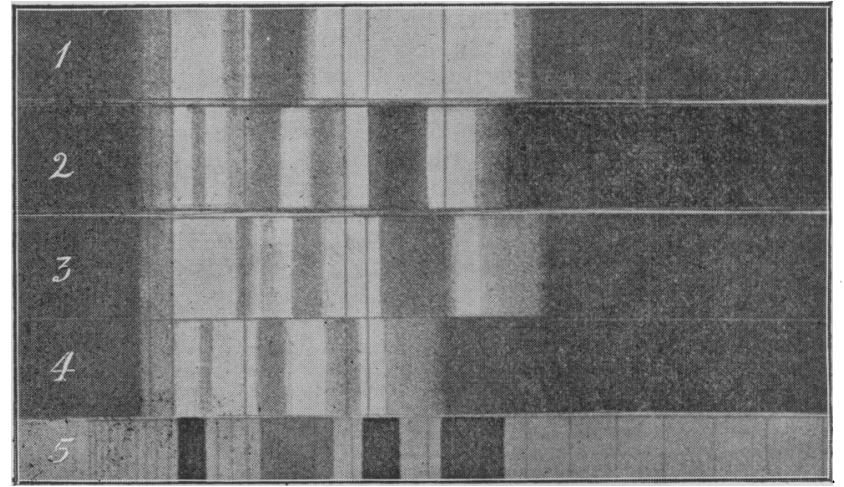

Hig. I. - (1) Acid tæematopurptıyrı. (2) Alkaline bæmatoporphyrin. (3) Acid urohæmatoporphyrin. (4) Alkaline urohæmatoporphyrin. (5) Meio-de oxyhæmatoporphyrin, or a-hæmatoporphyrin, the red ally of urohæmatoporporphyrin. (Nos. I to 4 are from the charts accompanying:MacMunn's paper

Mr. Cant's case was that of a woman, aged 40, with exophthalmic goître, who had excreted red urine for three years (corpuscles $2,250,000$ per c.mm. and $\mathrm{HBO}_{2} 40$ per cent. of normal). She had taken a good deal of sulphonal. There was some patchy pigmentation of skin, and bullæ filled with a red alkaline fluid. To three of these urines Dr. Halliburtion ${ }^{7}$ alludes on p. 751 of his Textbook (1891), in a footnote, where he states,that MacMunn regards this red pigment as " intermediate between urohæmatoporphyrin and hæmatoporphyrin." He refers the reader to two other similar cases (described by Drs. Ranking and Pardington ${ }^{8}$ ), which occurred in neurotic women and terminated fatally. The spectroscopic report on these two urines was made by Dr. MacMunn - the pigment was the same as in the first four cases, of deep garnet-red colour, yielding a four-banded spectrum resembling urohæmatoporphyrin, but differing, on careful comparison, in the position of the wave lengths of the absorption-bands : these were, however, not published, nor was the pigment named.

Two other cases of Burgundy-red urines were met with in 1890 , both by Dr. Vaughan Harley ${ }^{\circ}$-one in Edinburgh (in the Royal Infirmary under Dr. John Wyllie), the other in Christiania. Both were of - women who had been taking sulphonal, and who exhibited "nerve disturbances" and sleeplessness. The urine had no proteid, blood, or bile; in the foreign case the wave lengths of the centres of the $a b-$ sorption-bands were published : first band at $\lambda 562$, second at $\lambda 526$, third at $\lambda 482$, besides a feeble absorption in the violot.

On March 2ist, I891, Dr. Halliburton showed to the Physiological Society a specimen of red urine from a case of a lady, aged 30 , who had excreted the pigment for seven weeks. She had been taking sulphonal since the previous November and for more than a year had suffered from melancholic monomania. The urine was similar on examination to that of the former eight cases. The specimen was sent him by Drs. Blandford and Alliot, of Sevenoaks.

In 1894 Dr. Oswald, ${ }^{10}$ then assistant-physician to the Glasgow Royal Asylum, watched a case of mania in a woman to whom large doses of sulphonal were given. Between April and August she took 2,200 grs. of sulphonal, and at intervals during that time excreted a "claret"-coloured urine, which had no bile and did not give the guiac test. Though the case was described as an example of hæmatoporphyrinuria, there is now no doubt that the pigment was not urohæmatoporphyrin, but the red ally of it.

In December, 1896, I saw for the first time a Burgundy-red urine, sent me from the wards in the Western Infirmary Glasgow, from a patient under the care of Dr. McCall Anderson. 11

The urine contained no proteid, sugar, blood, or bile, gave 